\title{
Gambaran kadar trombosit dan hematokrit pada pasien diabetes tipe 2 dengan kaki diabetik di BLU RSUP Prof. Dr. R. D. Kandou Manado
}

\author{
${ }^{1}$ Daniel Ruscianto \\ ${ }^{2}$ Linda W. A. Rotty \\ ${ }^{2}$ Karel Pandelaki
}

\author{
${ }^{1}$ Kandidat Skripsi Fakultas Kedokteran Universitas Sam Ratulangi Manado \\ ${ }^{2}$ Bagian Ilmu Penyakit Dalam Fakultas Kedokteran Universitas Sam Ratulangi \\ Email: Danielruscianto12109@gmail.com
}

\begin{abstract}
Diabetes mellitus (DM) is a metabolic disease characterized by hyperglycemia due to impaired insulin activity, or both. Uncontrolled DM will lead to chronic complication, such as microangiopathy, macroangiopathy. and neuropathy. Diabetic foot is one of the chronic complications. This complication is associated with abnormality of thrombocyte and hematocrit levels that influence the blood flow. This study aimed to find out the profile of thrombocyte and hematocrit levels in patients with type $2 \mathrm{DM}$ with diabetic foot at Prof. Dr. R. D. Kandou Hospital Manado. There were 25 patients type 2 DM with diabetic foot as samples consisted of:10 males (40\%) and 15 females (60\%). The mean of hematocrit level in males was $35.20 \%$ and in females was $28.40 \%$. The mean of thrombocyte level was $391.4 \times 10^{3} / \mathrm{mm}^{3}$.
\end{abstract} Keywords: diabetic foot, thrombocyte, hematocrit

\begin{abstract}
Abstrak: Diabetes melitus (DM) merupakan suatu kelompok penyakit metabolik dengan karakteristik hiperglikemia yang terjadi karena kelainan sekresi insulin, kerja insulin atau keduannya. Hiperglikemi pada DM yang tidak terkontrol menyebabkan komplikasi kronis, seperti mikroangiopati,makroangiopati dan neuropati. Kaki diabetes merupakan salah satu komplikasi kronis. komplikasi ini berkaitan dengan kelainan kadar trombosit dan hematokrit yang mempengaruhi peredaran darah. Tujuan penelitian ini adalah untuk mengetahui gambaran kadar trombosit dan hematokrit pada pasien diabetes tipe 2 dengan kaki diabetik di BLU RSUP Prof. R. D. Kandou Manado. Terdapat 25 pasien dengan DM tipe 2 yang memiliki komplikasi kaki diabetes yang menjadi sampel penelitian ini. Berdasarkan distribusi jenis kelamin perempuan sebanyak 15 pasien (60\%) dan pada pasien laki-laki sebanyak 10 pasien (40\%). Rata-rata kadar hematokrit pasien laki-laki adalah 35.20\% dan perempuan adalah $28.40 \%$. Rata rata kadar trombosit pasien adalah $391,4 \times 10^{3} / \mathrm{mm}^{3}$.
\end{abstract}

Kata kunci: kaki diabetes, trombosit, hematokrit

Kesehatan merupakan salah satu hal penting dalam menunjang kesejahtraan manusia. Menurut Undang-undang No.9 tahun 1960, Bab 1 "kesehatan ialah keadaan yang meliputi kesehatan badan, rohani dan sosial dan bukan hanya keadaan bebas penyakit, cacat dan kelemahan.” Kesehatan dapat dipengaruhi oleh pola hidup yang kurang baik, keadaan ini juga dapat menimbulkan berbagai penyakit seperti diabetes. ${ }^{1}$

Diabetes melitus (DM) merupakan suatu kelompok penyakit metabolik dengan karakteristik hiperglikemia yang terjadi karena kelainan sekresi insulin, kerja insulin atau keduanya. Hiperglikemia kronik pada DM berhubungan dengan kerusakan jangka panjang, disfungsi, atau kegagalan beberapa organ tubuh, terutama mata, ginjal, saraf jantung dan pembuluh 
darah. $^{2}$

Menurut penelitian epidemiologi tahun 2013 pada penduduk usia $\geq 15$ tahun, proporsi DM, toleransi glukosa terganggu (TGT), dan gula darah puasa (GDP) terganggu oleh riset kesehatan dasar (Riskesdas) ialah DM 6,9\%, TGT 29,9\% dan GDP terganggu 36,6\%. ${ }^{3}$ Diperkirakan bahwa pada tahun 2030 prevalensi DM di Indonesia mencapai 21,3 juta orang (Diabetes Care, 2004). Hasil Riskesdas tahun 2007, diperoleh bahwa proporsi penyebab kematian akibat DM pada kelompok usia 45-54 tahun di daerah perkotaan menduduki ranking ke-2 yaitu 14,7\%, dan daerah pedesaan, DM menduduki ranking ke-6 yaitu 5,8\%. Kematian yang tinggi di sebabkan oleh komplikasi diabetes yang tidak terkontrol. ${ }^{4}$

Penyakit DM yang tidak terkontrol menyebabkan komplikasi kronis, baik mikroangiopati maupun makroangiopati. ${ }^{5}$ Kaki diabetes merupakan salah satu komplikasi kronik DM yang paling ditakuti dan sering berakhir dengan kecacatan dan kematian. Terjadinya masalah kaki diabetes diawali adanya hiperglikemia pada penyandang DM yang menyebabkan kelainan neuropati dan pembuluh darah. Neuropati akan mengakibatkan berbagai perubahan pada kulit dan otot, yang kemudian menyebabkan terjadinya perubahan distribusi tekanan pada telapak kaki dan selanjutnya mempermudah terjadinya ulkus. Aliran darah yang kurang juga menambah rumitnya pengelolaan kaki diabetes. ${ }^{6}$

Perubahan aliran darah menyebabkan kerusakan endotel sehingga menurunkan sintesis nitrit oxide (NO). NO berfungsi sebagai vasodilator pembuluh darah dan membatasi aktivasi trombosit. Hal ini menyebabkan meningkatnya aktivasi trombosit dan sistem pembekuan. penurunan produksi NO juga menyebabkan dilatasi pembuluh darah terhambat. ${ }^{7,8}$ Peningkatan hematokrit dapat mengakibatkan kecepatan aliran darah terganggu. Hal ini berkaitan dengan viskositas darah yang meningkat menyebabkan terjadinya vasokonstriksi pembuluh darah. ${ }^{9}$ Peningkatan viskositas dan hematokrit disebabkan oleh peningkatan osmolalitas yang menyebabkan peningkatan permeabilitas kapiler. Peningkatan diuresis juga menyebabkan menurunnya volume plasma dan meningkatnya hematokrit. Peningkatan viskositas darah, dapat berkembang menjadi trombosis dan emboli. ${ }^{10,11}$

Penelitian ini bertujuan untuk mendapatkan gambaran kadar trombosit dan hematokrit pada pasien diabetes tipe 2 dengan kaki diabetik di poliklinik kaki BLU RSUP Prof. R. D. Kandou Manado.

\section{METODE PENELITIAN}

Jenis penelitian yang digunakan ialah deskriptif dengan pendekatan potong lintang. Penelitian ini dilaksanakan di poliklinik kaki dan rawat inap bagian ilmu penyakit dalam RSUP Prof. Dr. R.D. Kandou Manado. Populasi penelitian ini ialah Pasien DM tipe 2 dengan komplikasi kaki diabetes yang datang di Poliklinik kaki dan rawat inap dalam periode tersebut sebesar 25 pasien. Definisi Operasional DM ialah pasien yang telah terdiagnosis Diabetes melitus tipe 2. Hematokrit adalah persentase volume yang mengandung eritrosit. Nilai normal hematokrit untuk pria $42 \%-54 \%$ dan wanita $38 \%-46 \% .^{12}$ Jumlah trombosit normal 150.000-400.000 $/ \mathrm{mm}^{3}{ }^{13}$

\section{HASIL PENELITIAN}

Berdasarkan Tabel 1 terlihat bahwa penderita DM tipe 2 dengan kaki diabetik terbanyak pada pasien dengan jenis kelamin perempuan sebanyak 15 pasien (60\%) dan pada pasien laki-laki sebanyak 10 pasien (40\%). Berdasarkan tabel 2 terlihat bahwa penderita DM tipe 2 dengan kaki diabetik terbanyak pada rentang umur $<60$ tahun tahun dengan jumlah 16 pasien (64\%) dan $\geq 60$ tahun sebanyak 9 pasien (36\%). Berdasarkan tabel 3 terlihat bahwa distribusi terbanyak pasien DM dengan kaki diabetik dengan grade 3 sebanyak 10 pasien (40\%), kemudian grade 4 sebanyak 6 pasien (24\%) dan grade 5 sebanyak 6 pasien (24\%), kemudian grade 2 sebanyak 
2 pasien(8\%) dan grade 6 sebanyak 1(4\%). Tidak ada pasien dengan kaki diabetik grade 1. Berdasarkan tabel 4 hampir seluruh pasien memiliki kadar hematokrit rendah dengan jumlah pasien laki-laki sebanyak 9 pasien (36\%) dan perempuan 15 pasien (60\%), dan hanya 1 pasien (4\%) laki-laki dengan kadar hematokrit normal. Berdasarkan tabel 5 pada pasien laki-laki kadar hematokrit rata-rata adalah 35,20\% dan pada pasien perempuan adalah $28,40 \%$. Berdasarkan tabel 6 dapat dilihat terdapat 16 pasien (64\%) yang memiliki kadar trombosit normal. Rata rata kadar trombosit normal pasien adalah $327,6 \times 10^{3} / \mathrm{mm}^{3}$ dengan nilai tertinggi $390 \times 10^{3} / \mathrm{mm}^{3}$ dan nilai terendah $206 \times 10^{3} / \mathrm{mm}^{3}$. Pasien yang mengalami trombositosis sebanyak 9 pasien (36\%) dan tidak ada pasien yang mengalami trombositopenia.

Tabel 1. Distribusi pasien berdasrkan jenis kelamin

\begin{tabular}{ccc}
\hline $\begin{array}{c}\text { Jenis } \\
\text { Kelamin }\end{array}$ & Frekuensi & (\%) \\
\hline Laki-Laki & 10 & 40 \\
Perempuan & 15 & 60 \\
Total & 25 & 100 \\
\hline
\end{tabular}

Tabel 2. Distribusi pasien berdasarkan umur

\begin{tabular}{ccc}
\hline Usia & Jumlah & $(\%)$ \\
\hline$<60$ tahun & 16 & 64,0 \\
$\geq 60$ tahun & 9 & 36,0 \\
Total & 25 & 100,0 \\
\hline
\end{tabular}

Tabel 3. Distribusi pasien berdasarkan grade

\begin{tabular}{ccc}
\hline $\begin{array}{c}\text { Grade Kaki } \\
\text { diabetik }\end{array}$ & Jumlah & $(\%)$ \\
\hline Grade 1 & 0 & 0 \\
Grade 2 & 2 & 8,0 \\
Grade 3 & 10 & 40,0 \\
Grade 4 & 6 & 24,0 \\
Grade 5 & 6 & 24,0 \\
Grade 6 & 1 & 4,0 \\
Total & 25 & 100 \\
\hline
\end{tabular}

Tabel 4. Distribusi pasien berdasarkan kadar hematokrit

\begin{tabular}{cccc}
\hline Jenis & & & \\
Kelamin & Rendah & Normal & Tinggi \\
\hline Laki-laki & 9 & 1 & 0 \\
Perempuan & 15 & 0 & 0 \\
\hline Total & 24 & 1 & 0 \\
\hline
\end{tabular}

Tabel 5. Rata-rata kadar hematokrit

\begin{tabular}{cc}
\hline Jenis Kelamin & $\begin{array}{c}\text { Kadar Hematokrit } \\
\text { Rata-rata }\end{array}$ \\
\hline Laki-laki & $35,20 \%$ \\
Perempuan & $28,40 \%$
\end{tabular}

\section{BAHASAN}

Pada penelitian yang dilakukan di poliklinik kaki bagian ilmu penyakit dalam RSUP Prof. Dr. R.D. Kandou Manado, didapati sebanyak 25 pasien yang menderita DM tipe II dengan kaki diabetik dan lebih banyak diderita oleh pasien perempuan dibanding pasien laki-laki. Hal ini tidak sejalan dengan penelitian yang dilakukan di RSUP Dr M. Djamil Padang oleh Decroli dkk, dari 38 pasien terdapat 27 pasien laki-laki (71\%) dan 11 pasien perempuan (29\%). ${ }^{14}$ Prevalensi penyakit arteri perifer lebih banyak pada laki laki di banding pada perempuan, terutama pada orang muda. ${ }^{15}$

Pada Tabel 2 dapat dilihat bahwa penderita DM tipe 2 dengan kaki diabetik terbanyak memiliki umur $<60$ tahun hal ini sejalan dengan penelitian yang dilakukan oleh Mahfud MU(2012), dari 54 pasien terdapat 36 pasien(66,7\%) pada rentang umur 51-60 tahun. ${ }^{16}$ Insiden dan prevalensi ulkus diabetik meningkat sesuai dengan bertambahnya usia. Prevalensi dari komplikasi kaki diabetik meningkat 3\% pada penderita DM usia di atas 40 tahun dan $6 \%$ pada usia di atas 60 tahun. ${ }^{14}$

Pada Tabel 3 dapat dilihat bahwa grade kaki diabetik terbanyak pada grade 3 dengan jumlah sebanyak 10 pasien (40\%), kemudian grade 4 sebanyak 6 pasien (24\%) dan grade 5 sebanyak 6 pasien (24\%). Grade 3 dibagi atas 2 jenis yaitu ulkus neuropati dan ulkus neuroiskemi. 
Ruscianto, Rotty, Pandelaki: Gambaran kadar trombosit...

Tabel 6. Distribusi pasien berdasarkan kadar trombosit

\begin{tabular}{cccccc}
\hline Kadar Trombosit & Jumlah & $(\%)$ & $\begin{array}{c}\text { Rata- } \\
\text { rata }\end{array}$ & $\begin{array}{c}\text { Nilai } \\
\text { Tertinggi }\end{array}$ & $\begin{array}{c}\text { Nilai } \\
\text { Terendah }\end{array}$ \\
\hline Trombisitopenia & 0 & 0 & - & - & - \\
Normal & 16 & 64.0 & 327.6 & 390 & 206 \\
\hline Trombositosis & 9 & 36.0 & 504.7 & 706 & 411 \\
\hline
\end{tabular}

Ulkus neuropati ditandai dengan kalus sebagai respon dari tekanan yang tinggi, kalus yang terbentuk harus dilakukan perawatan yang teratur dengan membuang bagian kalus. Kalus yang tidak diangkat akan menyebabkan ulkus dan ulkus ini biasanya tidak nyeri. Nyeri akan timbul sebagai tanda dari infeksi. Ulkus neuroiskemi biasa muncul di bagian tepi dari kaki ditandai oleh bercak kemerahan yang akan menjadi ulkus, nyeri yang timbul disebabkan oleh iskemik itu sendiri atau oleh infeksi. Infeksi yang timbul akan menyebabkan terjadinya nekrosis jaringan. ${ }^{17} 50-80 \%$ orang dengan diabetes di seluruh dunia mempunyai pengetahuan yang rendah dan kurang dalam kaitannya dengan penyakit, komplikasi serta pengelolaan penyakit mereka. ${ }^{18}$

Pada Tabel 4 hampir seluruh pasien memiliki kadar hematokrit rendah dengan jumlah pasien laki-laki sebanyak 9 pasien (36\%) dan perempuan 15 pasien (60\%), dan hanya 1 pasien(4\%) laki-laki dengan kadar hematokrit normal. Pada tabel 1 dapat dilihat bahwa pada pasien laki-laki kadar hematokrit rata-rata adalah 35,20\% dan pada pasien perempuan adalah 28,40\%. Kadar hematokrit yang rendah bisa disebabkan oleh beberapa faktor salah satunya adalah perdarahan yang disebabkan oleh ulkus. ${ }^{19}$ Ulkus yang tidak sembuh menyebabkan terjadinya anemia kronis, hal ini diperburuk dengan meningkatnya kekakuan membran sel darah merah yang terjadi pada pasien diabetes, membran sel darah merah yang kaku mengakibatkan sel darah merah akan sulit melewati kapiler pembuluh darah dan menyebabkan kerusakan endotelial sehingga penyembuhan luka pada pasien diabetes akan menjadi lambat. ${ }^{20}$
Pada Tabel 2 dapat dilihat terdapat 16 pasien (64\%) yang memiliki kadar trombosit normal dengan rata rata kadar trombosit normal pasien adalah 327,6 x $10^{3} / \mathrm{mm}^{3}$. Hal ini sejalan dengan penelitian yang dilakukan oleh Puspita ND dari 20 pasien diabetes melitus tipe 2 dengan kaki diabetik terdapat 14 pasien yang memiliki kadar trombosit normal dan rerata kadar trombosit adalah $368250,00 / \mathrm{mm}^{3}$. Pasien yang mengalami trombositosis sebanyak 9 pasien (36\%), trombositosis yang dialami pasien dikarenakan inflamasi dan perdarahan pada kaki dengan ulkus. $^{21}$ Trombosit memainkan peran integral dalam hubungan antara fungsi pembuluh darah dan trombosis, kelainan dalam biologis trombosit tidak hanya meningkatkan atrelosklerosis tetapi juga mempengaruhi akibat dari gangguan plak dan artherotrombosis. Di dalam sel endotel trombosit menyerap glukosa yang tidak terkendali kondisi hiperglikemia dan menghasilkan tekanan oksidatif, selanjutnya terjadi peningkatan agregasi trombosit pada pasien $\mathrm{DM}^{8}$

\section{SIMPULAN}

Berdasarkan hasil penelitian dapat disimpulkan bahwa rerata kadar hematokrit pasien laki-laki 35,20\% dan pasien perempuan $28,40 \%$. Rerata kadar trombosit ialah 391,4 x $10^{3} / \mathrm{mm}^{3}$. Penderita DM dengan kaki diabetik terbanyak pada grade 3.

\section{DAFTAR PUSTAKA}

1. Undang-Undang Nomor 9 tahun 1960. Pokok-pokok Kesehatan Bab 1 Pasal 2.

2. American Diabetes Assosiation. Diagnosis and Classification of Diabetes Melitus. Diabetes Care. 2015. [Cited 
3 November 2015]. Tersedia: http://care.diabetesjournals.org/conte nt/31/Supplement_1/S55.full.

3. InfoDATIN. Situasi dan analisis diabetes, 2014. [Cited 3 November 2015]. Tersedia: http://www.pusdatin.kemkes.go.id/res ources/download/pusdatin/infodatin/i nfodatin-diabetes.pdf.

4. Kementrian Kesehatan Republik Indonesia. Tahun 2030. Prevalensi Diabetes Melitus di Indonesia Mencapai 21,3 Juta Orang. [Cited 18 September, 2015]. Tersedia: http://www.depkes.go.id/article/view/ 414/tahun-2030-prevalensi-diabetesmelitus-di-indonesia-mencapai-213juta-orang.html .

5. Waspadji S. Komplikasi Kronik Diabetes: Mekanisme Terjadinya, Diagnosis, dan Strategi Pengelolaan. Dalam: Setiati S, Alwi I, Sudoyo AW, Setiyohadi B, Simadibrata M, editor. Buku Ajar Ilmu Penyakit Dalam (6th ed). Jakarta: Pusat Penerbit Ilmu Penyakit Dalam, 2014; p. 2359.

6. Waspadji S. Kaki Diabetes. Dalam: Setiati S, Alwi I, Sudoyo AW, Setiyohadi B, Simadibrata M, editor. Buku Ajar Ilmu Penyakit Dalam (6th ed). Jakarta: Pusat Penerbit Ilmu Penyakit Dalam, 2014; p. 2367-8.

7. Setiabudy D. Hemostasis dan trombosit (4th ed). Jakarta: FKUI, 2009; p. 45.

8. Clark N. Peripheral Arterial Disease in People with Diabetes. American Diabetes Assosiation. 2003. [Cited 11 Januari 2016]. Tersedia: http://care.diabetesjournals.org/conte nt/26/12/3333.full.pdf+html.

9. Lumingkewas CAY, Rotty LWA, Pandelaki K. Hubungan Lama Terjadinya DMT2 Dengan Hematokrit Pada Pasien DMT2 di Poliklinik Endokrin BLU RSUP Prof. Dr. R. D. Kandou Manado. e-Clinic. 2014;2(2): 2.

10.Irawati L. Viskositas darah dan aspek medisnya. Majalah Kedokteran Andalas. 2010;34(2):107.

11.Irace C, Carallo C, Scavelli F, Maria SDF, Teresa E, Agostino G. Blood viscosity in subjects with normoglycemia and prediabetes. Diabetes Care. 2013;37:489.
12.MedicineNet.com. Hematocrit.2015. [Cited 2 Oktober 2015]. Tersedia: http://www.medicinenet.com/hemato crit/page2.htm.

13. Medlineplus. Platelet count. 2015. [Cited 2 Oktober 2015]. Tersedia: https://www.nlm.nih.gov/medlineplus /ency/article/003647.htm.

14.Decroli E, Karimi J, Manaf A, Shahbuddin S. Profil Ulkus pada Penderita Rawat Inap di Bagian Penyakit Dalam RSUP Dr. M. Djamil Padang. Digital Journal.2008.H.6. [Cited 8 Januari 2016]. Tersedia: http://indonesia.digitaljournals.org/in dex.php/idnmed/article/download/561 1557

15.Nogren WR, Hiatt JA Dormandy. Inter Society Consensus for the Management of Peripheral Arterial Disease. Journal of Vascular Surgery, 2007. [Cited 8 januari 2016]. Tersedia:

http://www.jvascsurg.org/article/S074 1-5214(06)02296-8/fulltext.

16.Mahfud MU, Widyatmoko S, Sulistyani. Hubungan perawatan kaki diabetes melitus tipe 2 dengan kejadian ulkus diabetik di RSUD Dr. Moewardi. Eprints UMS. 2012. [Cited 9 januari 2016]. Tersedia: http://eprints.ums.ac.id/22557/9/NAS KAH_PUBLIKASII.pdf.

17.Edmons ME, Alethea V.M. Foster, Lee J. Sanders. A practical manual of diabetic foot care. 2004. p. 62-3. [Cited 2 Oktober 2015]. Tersedia: http://www.algadam.net/images2/Pra ctical_Manual_Diabetic_FootCare.pd f.

18.Fauziyah NF, Widyatmoko S, Candrasari A. Hubungan Pengetahuan Pasien Diabetes Melitus Tipe 2 Tentang Resiko Terjadinya Ulkus Diabetik dengan Kejadian Ulkus Diabetik di RSUP Dr. Moewardi. Eprints UMS. 2012. [Cited 9 januari 2016]. Tersedia: http://eprints.ums.ac.id/22552/9/NAS KAH_PUBLIKASII.pdf.

19.Davis CP. Hematocrit blood test. Shiel WC, editor. Emedicine Health. 2014. [Cited 9 januari 2016]. Tersedia: http://www.emedicinehealth.com/he matocrit_blood_test/page4_em.htm 
Ruscianto, Rotty, Pandelaki: Gambaran kadar trombosit...

20.Hariani L, Perdanakusuma D. Perawatan ulkus diabetes. Journal Unair. [Cited 9 Januari]. Tersedia: http://journal.unair.ac.id/downloadfullpapers-

02.\%20Perawatan\%20Ulkus\%20Diab etes.pdf.

21.Medscape. Secondary Thrombocytosis. 2015. [Cited 16 Januari 2016] Tersedia:

http://emedicine.medscape.com/articl e/206811-overview\#showall 